\title{
Hacia el rescate del método socrático en el aprendizaje actual del derecho procesal ${ }^{*}$
}

\author{
Enrique Letelier Loyola"
}

Recibido: 5 de julio de 2016 • Aprobado: 16 de mayo de 2017

DOI: $10.22395 /$ ojum.v16n3la5

\section{RESUMEN}

En este artículo se busca destacar la importancia del pensamiento crítico en el proceso de enseñanza y aprendizaje del derecho procesal, planteando como cuestiones previas las preguntas sobre qué enseñamos como Derecho, por qué es necesario enseñarlo y cómo deberíamos hacerlo. En el ámbito de las metodologías de enseñanza y aprendizaje del derecho, el denominado método socrático parece ser muy idóneo para entender el fenómeno normativo, pues obliga a los enseñantes y aprendices a formular preguntas siguiendo las reglas del pensamiento y a construir las repuestas en un contexto de diálogo. Ello facilita que se desarrollen las distintas etapas del pensamiento hasta llegar al pensamiento crítico, que es reflexión sobre sí mismo. El desarrollo de un método como el socrático permite abandonar el modelo catedrático tradicional, facilita el avance y demostración de las competencias de los estudiantes y puede aplicarse en armonía con el uso de las nuevas tecnologías de la comunicación.

Palabras clave: Enseñanza-aprendizaje; derecho procesal; método socrático; pensamiento crítico; competencias.

El presente trabajo hace parte de los procesos de investigación que adelanta el autor en la Facultad de Ciencias Jurídicas de la Universidad de Antofagasta (Chile).

* Abogado, Magíster y Doctor en Derecho. Profesor asociado, Derecho Procesal, Facultad de Ciencias Jurídicas, Universidad de Antofagasta, Chile. Doctor en Derecho por la Universidad de Salamanca. E-mail: enrique. letelier@uantof.cl. 


\title{
In the rescue of the Socratic method in current learning of procedural law
}

\begin{abstract}
This article is intended to remark the importance of critical thought in the learning and teaching process of procedural law, stating some questions about what we are actually teaching as Law, why is it necessary to teach law, and how we should do it. Concerning methodologies to teach and learn the law, the Socratic method seems to be the suitable method to understand the normative phenomenon, since it obliges teachers and students to formulate questions following rules of thinking and construct responses within a context of dialogue. This facilitates the development of several stages of thinking until reaching the critical thinking which implies a self-reflection. The development of a method similar to the Socratic method allows setting aside the traditional teaching model, facilitates progress and demonstration of students' skills, and it can be applicable in conjunction with new communication technologies.
\end{abstract}

Key words: Teaching-learning; procedural law; Socratic method; critical thinking; competences. 


\section{INTRODUCCIÓN}

\section{Por qué seguimos ocupados en la enseñanza del Derecho}

Es un hecho poco discutible que gran parte de quienes ejercemos la docencia universitaria carecemos de una formación como pedagogos. Ello se traduce, en general, en que fuera de los dominios de las disciplinas que abarcan nuestras particulares profesiones no disponemos de las herramientas necesarias para desarrollar metodologías de enseñanza-aprendizaje, diseñar e intervenir en planes de estudio y currículos, planificar actividades curriculares y desarrollar procesos de evaluación.

$\mathrm{Ni}$ aun todos los viejos maestros de las tradicionales y prestigiosas facultades de Derecho poseían formación en docencia universitaria, a pesar que lograron fundar y desarrollar escuelas que hasta hoy nos nutren, asociando a sus saberes e inteligencia, atributos de habilidad, intuición e ímpetu en una virtuosa relación dirigida a la enseñanza del derecho. Ellos mismos se ocuparon de llamar la atención en su tiempo acerca de la realidad universitaria y la formación de los abogados.' Como tantos en Italia, en tiempos de la reforma universitaria de comienzos del siglo pasado, el joven profesor Giorgio Pasquali y el maestro de florentino Piero Calamandrei en su obra L'Università di Domani (1923) formularon un poco auspicioso diagnóstico de la enseñanza del derecho y plantearon vigorosamente pro-

Véase una estupenda síntesis de quienes han sido durante el siglo XX los grandes procesalistas en Europa y Latinoamérica, en Gozaíni (2005), passim. puestas de cambio. ${ }^{2}$ En nuestra América el reconocido jurista uruguayo Eduardo J. Couture se ocupó también de la enseñanza del Derecho, no sólo practicándola, sino también plasmando sus reflexiones en bellos y preclaros textos, como Los Mandamientos del Abogado (1949), cuya lectura habitual nos permite hallar la profundidad de su pensamiento en su prosa elegante y de estilo simple. ${ }^{3}$

2 L'Università di Domami (Foligno: Campitelli Edit., 1923), fue traducida al castellano por Alberto Bianchi y publicada en Buenos Aires por la prestigiosa editorial Ediciones Jurídicas Europa-América (EJEA) en 1961. En la presentación de Calamandrei, sus aseveraciones no pueden ser más claras (y de pasmosa actualidad):

"Esta, mi contribución significa, pues, ante todo, una implícita adhesión a las piedras angulares de la reforma que Pasquali anhela, que pueden ser resumidas en los siguientes puntos: 1) libertad de estudio y consiguiente abolición de las cursos obligatorios; 2) abolición de los exámenes especiales; 3) prevalencia de las ejercitaciones sobre las lecciones catedráticas; 4) autonomías didácticas de las facultades; 5) transformación del doctorado en título meramente científico; 6) examen estatal a los efectos profesionales." (cursivas en el original).

3 Desde su profundo pensamiento Couture postulaba una visión muy rica de la abogacía: al mismo tiempo como arte y política, como ética y acción. La abogacía como arte, pues el manejo de las leyes se sujeta a unas reglas que el abogado debe saber dominar; empero "el abogado está hecho para el derecho y no el derecho para el abogado." Es a la vez política, pues el abogado es un activo en la lucha por la libertad; "desde la autoridad que crea el derecho o desde la defensa que pugna por su justa aplicación, el abogado es quien desata muchas veces ráfagas de tempestad y puede contenerlas." Como ética el ejercicio de la profesión de abogado es el ejercicio de la virtud, debiendo lealtad para con el cliente, el juez y el propio adversario; el abogado "puede hacer de su cometido, se ha dicho, la más nombre de todas las profesiones o el más vil de los oficios." La abogacía es además acción: "La profesión demanda, en todo caso, el sereno sosiego de la experiencia y del adoctrinamiento de la justicia; pero cuando la anarquía, el despotismo o el menosprecio a la condición del hombre sacuden las instituciones y hacen temblar los derechos 
No sería cierto que afirmásemos haber llegado a esta centuria arrastrando menos dudas y cavilaciones que antes. Por el contrario, bastantes años llevan ya las universidades en procesos de reforma como para decir que han cristalizado en un solo modelo idóneo para el rol que la sociedad les demanda. Y si en su tiempo llevaba mucha razón Ortega cuando, comenzando el siglo pasado, en el discurso pronunciado en el Paraninfo universitario de Madrid proclamaba, entre muchas cosas, que la Universidad debe ser un centro de docencia e investigación científica, las ideas del ilustre pensador han de tenerse en cuenta por el lector actual: las universidades de hoy aspiran a convertirse en entidades complejas, es decir, erigirse en instituciones de educación superior donde se imparta enseñanza profesional, se desarrolle investigación científica de calidad -teorética y aplicada- y se desarrollen las artes como una manifestación relevante del ser humano, siendo además actores relevantes en la sustentabilidad social. La universidad no sólo requiere contacto con la ciencia, que es su "alma" y "dignidad", sino que "[N]ecesita contacto con la existencia pública, con la realidad histórica, con el presente, que es siempre un integrum y sólo se puede tomar en totalidad, sin amputaciones ad usum delphinis." ${ }^{4}$

individuales, entonces la abogacía es militancia en la lucha por la libertad." Vide y cf. COUTURE (1953) 16 y 17.

4 "¿En qué consiste - se preguntaba el filósofo madrileño - esa enseñanza superior ofrecida en la Universidad a la legión inmensa de los jóvenes? En dos cosas: a) La enseñanza de las profesiones intelectuales. 6) La investigación científica y la preparación de futuros investigadores." (...) Cf. Ortega y Gasset (1965), 24 y 75.
Por otro lado el generalizado paso del modelo de enseñanza universitaria con énfasis en el docente como poseedor de los conocimiento hacia uno con acento en el estudiante o aprendiz como sujeto activo en la gestión de su propio aprendizaje, mantiene vivas varias cuestiones sobre las que se debate desde mucho, como los diseños curriculares, la planificación docente, las metodologías innovadoras, la didáctica y los procesos de evaluación, amén de hacer surgir otras nuevas como la aplicación de las tecnologías de la información al aprendizaje y el impacto en los individuos de la denominada sociedad del conocimiento (sociedad del saber o knowledge society).

En algo más confuso a la vez que desafiante se ha tornado el panorama con la irrupción de los planes de estudio basados en competencias y demostración de resultados de aprendizaje, pues a la falta de univocidad en la definición del primero ha de sumarse la falta de precisión del segundo, de suerte que tantas definiciones y graduaciones existen cuantos autores se han dedicado a trabajar sobre tales conceptos. ${ }^{5} \mathrm{Y}$ si bien antes que definir parece preferible destacar los elementos sobre los que se construye una competencia (actitudinales, intelectivos o de conocimiento y las habilidades y destrezas) ${ }^{6}$,

Véase Kennedy (2007) 21 y sig.

6 González y González (2008, p. 206): "La competencia profesional, concebida desde una perspectiva compleja, es, por tanto, una capacidad que expresa cómo se manifiesta la personalidad del profesional en su desempeño, que posee:

- Una dimensión estructural o de contenido en la que se incluyen los componentes cognitivos (conocimientos, habilidades) y afectivos (motivos, valores). 
para justificar por qué aún hoy seguimos ocupados en el problema de la enseñanza del Derecho, hemos sólo de llamar la atención sobre dos de sus caracteres generalmente aceptados: las competencias son desarrollacionales, es decir, no se agotan al tiempo que se cumpla con el plan de estudios, sino que se despliegan progresivamente en el tiempo traspasando incluso hacia la vida profesional del aprendiz egresado ${ }^{7}$, y son contextuales, en el entendido han de diseñarse para su desarrollo en un contexto espacio temporal determinado y pensando en un aprendices reales y concretos, puesto que aquéllas tienen una indiscutible vocación práctica y han de demostrase en el logro de resultados. ${ }^{8}$

- Una dimensión funcional en la que se fusionan recursos personológicos tales como la perseverancia, la flexibilidad, la reflexión crítica del profesional en su desempeño, que expresan cómo la competencia regula su actuación en la profesión."

7 Las competencias han de instalarse y desarrollarse gradualmente, en diferentes medidas y estadios, pues deben preparan al individuo para aprender durante toda la vida (longlife learning).

El aprendizaje para toda la vida «es un marco filosófico y conceptual, y un principio organizativo de todas las formas de educación, basado en valores de inclusión, emancipación, humanísticos y democráticos; es global y parte integrante de la perspectiva de una sociedad basada en el conocimiento.» y cumple una función crítica en la forma de abordar los problemas de la educación actual. Así lo tiene declarado expresamente UNESCO a partir de la VI Conferencia Internacional sobre Educación de Adultos (CONFITEA VI, Belém do Pará, 2009) en el Marco de Acción de Belém (disponible en http://unesdoc. unesco.org/images/0018/001877/187789m.pdf).

8 Con ese predicamento el desarrollo de las competencias y la demostración de su logro permite que el aprendiz vincule el aprendizaje con sus propias experiencias de vida (aprender para aprender). "En el fondo -enseña Paulo Freire-, no somos sólo lo que heredamos ni únicamente lo que adquirimos, sino la relación dinámica y procesal de lo que here-

\section{QUÉ, POR QUÉ Y PARA QUÉ ENSEÑAMOS DERECHO}

Cuando en los albores del siglo XXI nos preguntamos sobre la enseñanza del Derecho, con especial énfasis en las metodologías adecuadas al proceso de enseñanza-aprendizaje, conviene detenernos en la formulación de tres preguntas que tras su simpleza esconden reflexiones de tremenda importancia: qué enseñamos cuando decimos enseñar Derecho, por qué lo hacemos y para qué.

Intentar una respuesta unívoca a la primera cuestión ha sido y seguirá siendo una empresa extremadamente difícil, cuando no imposible: sobre el objeto de nuestro oficio de enseñar se ha discutido y escrito tanto, que cuando menos hoy no resulta posible elaborar una Teoría del Derecho, pues el fenómeno normativo evoluciona, muta, se integra, se adecua, es permeable a las vicisitudes históricas. ${ }^{9}$

damos y lo que adquirimos." Vide Freire (2002) 103

Esto no quiere decir, sin embargo, que el aprendizaje se reduzca sólo al resultado de la experiencia directa; uno de las diferencias fundamentales entre humanos y animales es la capacidad de los primeros de aprender a través de la observación de modelos o maestros (aprendizaje observacional o vicario mediante modelos). Tal aprendizaje observacional reúne dos aspectos relevantes: es un aprendizaje silencioso, pues no requiere del aprendiz ninguna respuesta externa (corresponde al conocido "aprendizaje en teoría") y es un aprendizaje que debe complementarse con la práctica, siendo el proceso de ensayo / error es un condicionamiento que determina la probabilidad que lo aprendido por observación mejore o se consolide. Vide en extenso Maldonado López (2015) 137 y sig.

9 De manera muy preclara el procesalista rioplatense Augusto Mario Morello llamaba la atención sobre la confluencia de tres dimensiones que enriquecen el fenómeno jurídico: una visión constitucional, 
$\mathrm{Ni}$ aun en la disciplina que justifica esta presentación existe tal univocidad, por lo que preferimos afirmar, no sin cierta carga ideológica, que cuando enseñamos Derecho procesal enseñamos el Derecho del proceso.

Siguiendo esa propuesta, no menos relevante es la pregunta que intenta justificar la enseñanza del Derecho procesal. ¿Por qué lo enseñamos? Si reputadísimos juristas han propuesto distintas explicaciones acerca de la naturaleza del proceso, sus elementos y funciones, quiere decir que el proceso es un fenómeno complejo ${ }^{10}$; y lo es, porque traslada a la sede jurisdiccional un conflicto material, erigiéndose como una realidad espacio-temporal que contiene en sí un conflicto, antes meramente material y ahora procesal. Por lo pronto, he ahí una primera justificación: la complejidad del proceso como fenómeno. Pero además el proceso jurisdiccional ${ }^{11}$ es un fenómeno jurídico en que el Derecho se introduce en sus intersticios con reglas y principios, asignándole una o muchas formas de ser. Entonces, si hoy el proceso no escapa al fenómeno normativo -ni menos a la proliferación normativa a veces desprolija y poco coherente- se justifica enseñarlo y aprenderlo (y comprenderlo).
Atrás las preguntas del objeto y la justificación, las líneas que siguen redundarán sobre la pregunta de la finalidad: para qué enseñamos el Derecho y, como ya se sabe, Derecho procesal.

Sobre ello pueden intentarse muchas respuestas, mas preferiremos aquélla que por obvia no es menos compleja -asombrarse ante lo evidente es el primer paso del pensamiento-. La ciencia que nos ocupa -a pesar de su juventud e instrumentalidad defendemos la independencia y sistematicidad del Derecho procesal ${ }^{12}$ ha de incidir en la formación de abogados habituados a pensar. Con esta afirmación no pretendemos sino destacar el atributo fundamental de los abogados que de manera simple y magistral reclamaba Eduardo Couture cuando invitaba siempre a pensar, pues, afirmaba el viejo maestro uruguayo, el Derecho se aprende estudiando pero se ejerce pensando. ${ }^{13}$ Probablemente Couture, hombre de su tiempo pero con una gran visión del futuro, no se detuvo a meditar en el desarrollo de las llamadas competencias blandas ni de las competencias profesionales, como el razonamiento jurídico, la defensa de intereses ajenos o el desarrollo de soluciones jurídicas a problemas relevan- una dimensión social y una dimensión transnacional, "en cuya síntesis se aposenta lo dogmático en la concepción de una ciencia jurídica útil...". Vide y cf. Morello (2005) 34.

10 Una estupenda y sintética exposición de estos asuntos, relacionados con el proceso, puede verse en Devis Echandía (2002) 155 y sig.

1 La expresión es utilizada con toda propiedad por autorizada doctrina procesal española. Vide Gimeno (1981) passim.
12 Ramos Méndez (2004) 16 - 17.

13 Enseñaba Couture: "El pensar del abogado no es pensamiento puro, ya que el derecho no es lógica pura: su pensar es, al mismo tiempo, inteligencia, intuición, sensibilidad y acción. La lógica del derecho no es una lógica formal, sino una lógica viva hecha con todas las sustancias de la experiencia humana." Cf. Couture (1953) 29. 
tes, mas su exhortación no puede pasar inadvertida a quienes hoy enseñamos Derecho ni a quienes, en mayor medida, lo practican. ${ }^{14}$

A estas alturas el lector reparará en la ausencia de una pregunta habitual: cómo se enseña Derecho. Pero ésta, que reconduciremos a la metodología, estará constantemente interrogando a la que hemos anunciado como el eje de esta exposición, es decir, la finalidad.

14 No es causal, sin embargo, que las competencias profesionales, genéricas y específicas, resalten las capacidades de análisis, síntesis, planificación y evaluación.

Comentando el contenido del conocido Informe Tuning para Latinoamérica (2003) explican González y González (2008) 192 - 193: "La reforma curricular universitaria que tiene lugar en la actualidad en el proceso de convergencia europeo de educación superior, dirigido a lograr competitividad, empleabilidad y movilidad para los profesionales en Europa a partir de titulaciones fácilmente comparables y comprensibles, centra la atención en la formación en competencias profesionales (Tuning, 2003). La concepción de las competencias profesionales en el proyecto Tuning, el que analizaremos en detalle más adelante, reconoce su carácter complejo y las clasifica en dos tipos fundamentales: Genéricas (transversales, comunes a todas las profesiones). En estas competencias se incluyen elementos de orden cognitivo y de orden motivacional, y se expresan a través de las denominadas:

Competencias instrumentales, de orden metodológico o de procedimiento, tales como la capacidad de análisis y síntesis, de organización y planificación, y de gestión de información.

Competencias personales, tales como la capacidad para el trabajo en equipo, la habilidad para el manejo de las relaciones interpersonales, el compromiso ético.

Competencias sistémicas, que se manifiestan en el aprendizaje autónomo, la adaptación a nuevas situaciones, la creatividad y el liderazgo, entre otras. Específicas (relativas a una profesión determinada)." (negrillas en el original).

\section{LA URGENTE NECESIDAD DE PENSAR (EN) EL DERECHO}

Pensar acerca del Derecho no demanda sólo la tarea de hacerlo respecto del Derecho positivado -admitimos la tautología, desde que en nuestra visión el Derecho no es sino un acto de autoridad - sino también ejercitar el arte del pensamiento en su fase de génesis. Qué gran tarea toca al legislador reflexionar detenidamente el Derecho cuando, siguiendo los procedimientos pactados para su creación, debe decidir que determinados valores, ideas preponderantes o fuerzas modeladoras han de recibir una sanción de autoridad y convertirse en normas heterónomas y coercibles. ${ }^{15}$ Y como según se ha dicho el fenómeno normativo no sigue necesariamente una lógica formal, el riesgo de distonías, vacíos y incoherencias es permanente. Ello no carece de relevancia si acordamos (y defendemos) que de un sistema procesal, cualquiera sea su naturaleza, son exigibles los atributos de plenitud, coherencia y racionalidad ${ }^{16}$,

15 Explica Edgar Bodenheimer, antiguo profesor de la Universidad de California, que las fuerzas modeladoras del derecho son las fuerzas políticas, psicológicas, económicas y evolutivas de la sociedad que influyen en el desarrollo progresivo del derecho. Vide Bodenheimer (1946) 243.

16 Ha escrito Manuel de Rivacoba que "...es útil recordar ahora la función sintetizadora de la razón, que tiende a ordenar coherente y unitariamente sus contenidos, cualesquiera que éstos sean. De ahí, que, por más que en la creación del Derecho prepondere en definitiva lo voluntario, en la medida en que la voluntad vaya iluminada por la razón e intervenga, por tanto, ésta en la constitución del ordenamiento, es dable asegurar de él que estará libre de opugnaciones íntimas que lo maculen y dificulten o impidan su realización." Cf. Rivacoba Y Rivacoba (1981, p.195). 
cualidades perceptibles en el contenido de la decisión jurisdicional más relevante, la sentencia, que afectará finalmente a los justiciables. ${ }^{17}$

El ejercicio del hábito de pensar reconviene a quienes trabajamos con el Derecho, bien aplicándolo en decisiones provistas de autoridad, bien invocándolo como fundamento de peticiones al Estado, bien enseñándolo en las aulas universitarias. ${ }^{18}$ Sobre esta reconvención a pensar en el Derecho nos dentendremos unos instantes.

En el ejercicio profesional pensar en el derecho resulta fundamental: la vieja y tradicional fórmula que expresa "una buena demanda es el proyecto de una buena sentencia" no deja hoy de tener vigencia, pues, a pesar de la creciente configuración del juez como director del debate, la correcta formulación de la pretensión

17 En opinión de Luigi Ferrajoli su ausencia genera vicios que afectan la eficacia del Estado Constitucional de derecho, "... a causa de la posible incoherencia generada por normas que resulten inválidas al contrariar prohibiciones impuestas por normas superiores a la esfera de los decidible; o, a la inversa, por la posible falta de plenitud debida a la omisión de normas o decisiones en contraste con obligaciones impuestas a la misma esfera. Éstos son los dos posibles vicios del ordenamiento: las antinomias y las lagunas...". Cf. Ferrajoli (1999) 24.

18 Refiriéndose a su enseñanza, Augusto Mario Morello consideraba imprescindible repensar el Derecho. Los diversos factores internos y externos que inciden el fenómeno jurídico, en especial, la necesidad de alcanzar criterios hermenéuticos que logren conjugar las "verdades dogmáticas con un enfoque contextual" son indicativos que "el sistema del derecho se nutre fundamentalmente de valores, que rodean privilegiadamente a la persona, que es el centro solar de ese universo y que demanda la efectividad de las garantías para proveer a una tutela oportuna...". Vide y cf. Morello (2005) 33. y el oportuno ejercicio de las cargas y derechos que impone la ritualidad del proceso, garantizan a los justiciables la obtención de una sentencia motivada, a la vez que activan los controles para que los jueces cumplan con este deber. Tal vez lleva razón Couture cuando afirma que la jusrisprudencia la hacen los abogados, pues "en la formación de la jurisprudencia, y con ella del derecho, el pensamiento del juez es normalmente un posterius; el prius corresponde al pensamiento del abogado."19

Y es evidente que el llamado a pensar el Derecho se dirige también a los estudiantes. Hoy la invitación para los que tradicionalmente han sido destinatarios del proceso de enseñanza se transformen en actores de su propio de aprendizaje, es un llamado inevitable y poderoso. ${ }^{20} \mathrm{Al}$ conocimiento se acopla el juicio crítico como un complemento indispensable en la formación de los abogados. ${ }^{21}$ Este binomio no es antojadizo, pues los abogados en formación deben ser personas movidas por la duda, por el cuestionamiento, por las preguntas que exigen respuestas: bajo la filosofia de conversar para aprender, el desafío más relevante es ser capaz de

19 Couture (1953), p. 29.

20 Morello (2005) 35: "Capacitación, destreza, estrategias, enfoques, diligencias y severas exigencias éticas son obligaciones y guías a las que el abogado debe perseverancia; integran el contenido de la moderna formación universitaria." (cursivas en el original).

21 "El currículo de la Carrera de Derecho debe permitir al estudiante conocer el Derecho y sus principios fundamentales, adquirir juicio crítico y ser capaz de usarlo en la solución de problemas jurídicos.", declara en Chile el documento Criterios de Evaluación para Carreras de Derecho, elaborado por la Comisión Nacional de Acreditación (CNA). 
responder cuando se es preguntado, de formular preguntas por uno mismo y, tal vez el más dificil, de aceptar las correspondientes respuestas. ${ }^{22}$

El estado de permanente alerta y curiosidad ha de ser el de los aprendices; la pereza del pensamiento no es connatural a los jóvenes estudiantes, pues, como con toda razón ha descrito Martha Nussbaum, "¿acaso hubo alguna época de la historia humana en que los jóvenes no hicieran preguntas?"23

Es así que el desarrollo del pensamiento ha de ser una actividad que se despliegue generosamente en las aulas y foros universitarios, a la vez que un llamado para quienes como docentes cumplimos un rol de garantizadores del aprendizaje.

\section{ALGUNOS PASOS EN EL ARTE DE PENSAR}

El epígrafe de este párrafo no es fruto de una casualidad. Nos ha parecido conveniente recordar las ideas que de manera simple y brillante planteaba Jean Guitton promediando el siglo XX. En su obra Nuevo Arte de Pensar (1946), enseñaba el educador y filósofo francés que, para aprender a pensar, ante todo ha de cultivarse la capacidad de asombro. Paradojalmente, el primer paso en el camino del pensamiento crítico es tener la impresión que no se entiende incluso aquello que para muchos resulta evidente. ${ }^{24}$

22 Gadamer (2001) 533.

23 Cf. Nussbaum (2005) 43.

24 Explica el filósofo y escritor francés: "Por consiguiente, captamos la diferencia entre quien no piensa y quien piensa. Aun ante el misterio, el pri-
La disposición para el pensamiento crítico impone que la admiración sea un estado permanente, admiración que desde una óptica pasiva se confunde con "la extrañeza que nace en nosotros sin que medie esfuerzo alguno de nuestra parte en provocarla", y desde una activa, evoca una relación entre el sujeto y el objeto o el fenómeno proponiendo problemas y vislumbrando posibles formas de solución, en otras palabras "en prever lo que se verá, en preimaginar, o como dicen muchos, en prepercibir." Con esta disposición anímica anidada en el sujeto, sentencia Guitton: "Quien no sabe lo que busca, no sabe lo que encuentra." ${ }^{25}$

Los pasos en el arte de pensar podrían resumirse en los que siguen: la elección, la distinción, la contradicción.

Elegir y organizar, aconseja Guitton: "Comenzar por elegir (...), una idea directriz que luego habrá de organizar y, como decía Aristóteles, convendrá pensar este pensamiento: por lo demás el pensamiento solo existe en realidad cuando es reflexión sobre sí mismo...". ${ }^{26}$

La distinción está estrechamente vinculada con el uso de lenguaje. Distinguir, dividir; un primer paso del pensamiento correcto es disociar las ideas y nociones confundidas, dándole nombres diferentes para poder ser utilizadas por separado y oponerlas mutuamente. Para Platón "[El]

mero se dice siempre: «iPero, si esto es evidente!». Aun ante la evidencia, el segundo se repite: «No entiendo». El primer paso del pensamiento es una cierta ininteligencia ante lo que el mundo creía perfectamente comprensible." Cf. Guitton (2000) 12.

25 Cf. y vide Guitton (2000, p.14-17).

26 Ibíd. 43. 
buen dialéctico (...) debe dividir su tema según sus articulaciones naturales. Y esto implica que ha de encontrar en el tema líneas de partición, fronteras y suturas naturales. $^{27}$

El último procedimiento en el arte de pensar, radica en la contradicción. ${ }^{28}$ Así lo explica Guitton:

El pensamiento que pasó por la contradicción es un pensamiento experimentado; y si un pensamiento experimentado no es idéntico a un pensamiento probado, por lo menos ha ganado en este duro pasaje agilidad y ductilidad. ¿Qué podrá temer en adelante? Se ha apropiado de las razones del adversario (..... ${ }^{29}$

Pero agregamos un estadio complementario: el de la conversación. En esto ha insistido el filósofo alemán Hans-Georg Gadamer cuando explica que es la convivencia -no mera compañía- lo que nos eleva sobre el mundo animal -mas no nos separa de nuestra carácter natural- a tra27 Ibíd. 66.

28 Nussbaum (2005) 38: "La filosofía aparece cada vez que las personas son alentadas a pensar por sí mismas, cuestionándose a la manera de Sócrates. Para todos estos estudiantes, la filosofía viene a proporcionar algo que ante faltaba: un control activo o comprensión de las preguntas, la capacidad de hacer distinciones, un estilo de interacción que no descansa en la sola aserción y una contraaserción, todo lo cual encuentran importante para sus vidas y su relación consigo mismo y con los demás."

29 Guitton (2000, p.96) (cursivas nuestras). Agrega este autor, ibídem: "Alojar al adversario en su propia casa, autorizarle plenamente a que contradiga, es en el orden de los pensamientos algo semejante al valor. Podría pensarse que quien no obra de este modo es porque tiene miedo." vés del lenguaje humano como capacidad para comunicarnos. En la lingüisticidad de la convivencia está el sustrato de la comunicación:

Dentro de cualquier cultura hay acuerdos y concordancias. Con la expresión «concordancia» |Übereinkommen] el lenguaje indica que eso que designa no procede de una fundación expresa ni de la firma de un contrato, sino que se «recibe» [überkommen]. Así, también es significativo que el lenguaje diga que «encontramos» concordancias. Con ello la sabiduría del lenguaje nos dice que hay aquí dos compañeros distintos que se encuentran, como ocurre en cualquier cita. Si se pone en marcha el aprendizaje del lenguaje del otro, entonces puede resultar una convivencia reglada pacíficamente, aunque sólo sea dentro de límites. ${ }^{30}$

\section{EL MÉTODO SOCRÁTICO Y EL ARTE DE PENSAR (EN) EL DERECHO}

Decíamos que el pensamiento parte desde el asombro, incluso frente aquello que aparece como evidente. Y la invitación de Sócrates a sus discípulos discurre precisamente por similares cauces: cuestionar incluso aquello que nos viene dado por la tradición. ${ }^{31}$ Y son ideas que refuerza

30 Gadamer (1997, p.84-85).

31 Recordemos que la acusación de Meleto contra el filósofo ateniense gira en torno a tres puntos: investigar las cosas celestes y las subterráneas, no creer en los dioses y convertir el argumento más débil en el más fuerte (Plat., Apol., I, X). 
Nussbaum: "La tradición es un enemigo de la razón socrática." ${ }^{2}$

Si proponemos en un tema que inevitablemente se ve influido por el peso de la tradición, ése es el de la justicia. No decimos que la noción de la misma sea inmutable; muy por el contrario, se trata de una idea (y un ideal) sujeta a las valoraciones sociales, siempre históricas. No en vano existen tantas concepciones cuantos filósofos y juristas se han dedicado en serio a discutir y pensar en lo justo y la justicia.

Qué duda cabe que los abogados estamos llamados a pensar en la justicia y actuarla, por lo que es del todo aconsejable que acerquemos a nuestros estudiantes, desde jóvenes, a ese debate. Y más cierto aun es que los estudios de Derecho procesal, del Derecho del proceso, nos acercan a la noción de lo justo y aquello que podríamos llamar lo justo procedimental y lo justo material, pues es así como los conceptos de agravio, indefensión, tutela efectiva, derecho justicial material, función dikelógica de la casación, entre muchos, son -o deben ser personajes principales y frecuentes en las aulas en que se aprende Derecho procesal. ${ }^{33}$

Sobre ellos no hay dogma alguno, no hay verdad irrefutable que se pueda blandir contra los cambios y necesidades de la sociedad y los justiciables; no podríamos admitir arraigarlos en la categoría de

32 Nussbaum (2005), p. 39.

33 Sobre la relación entre la enseñanza del Derecho procesal y la ética, véase Tavolari Oliveros (2000, p. 642). nuestras creencias -Ortega siempre nos ha parecido poderosamente vigente $\sim$ y si ello sucediese, aun deberíamos admitir la posibilidad de errar. Aquí radica también nuestra libertad. ${ }^{34}$

A la justicia nos acercamos diariamente en las lecciones de Derecho procesal, desde la organización jurisdiccional y su administración, pasando por los diversos procedimientos, hasta el control de la respuesta jurisdiccional. Y las preguntas redundan siempre acerca de las ideas de justicia procedimental y justicia sustantiva o material, ¿no es legítimo que el estudiante de derecho procesal se pregunte por qué el juez debe ejecutar ciertas conductas y la partes han de cumplir unas cargas? ¿No es esperable que el mismo estudiante cuestione los estándares que el constituyente ha fijado para el debido proceso? ¿No tenemos los profesores de esta disciplina la asentada expectativa que nuestros estudiantes se pregunten y discutan qué harán cuando, ejerciendo la profesión como abogados o como jueces, les corresponda defender intereses ajenos o resolver la pretensiones de tutela y deban someterlas, incluso, al prisma de su propia concepción de lo justo ${ }^{35}$

34 Nussbaum (2005, p. 59) "No habremos engendrado ciudadanos verdaderamente libres en el sentido socrático a menos que formemos personas capaces de razonar por sí mismas y argumentar correctamente, capaces de entender la diferencia entre un razonamiento con validez lógica y otro lógicamente débil, de distinguir entre la estructura lógica de un discurso y la verdad de sus premisas."

35 La relación de colaboración entre el ejercicio de la abogacía y el desarrollo de la función jurisdiccional es evidente: "La enseñanza de la abogacía - que al igual que el estudio y entrenamiento, son permanentes - no puede perder de vista que los principios, las normas, las teorías generales, los estándares y las 
Ningún debate en torno al derecho nos parece estéril o necesariamente destinado a quedarse en el mundo de las ideas. ${ }^{36}$ El derecho es una realidad normativa llamada a ser aplicada; los debates en torno a un problema de relevancia jurídica, redundan en una propuesta de solución. El tema lo planteaba claramente un viejo y prestigioso procesalista español:

[Ocurre] en la Ciencia Jurídica, y en general en todas las ciencias sociales, que la aplicación, el caso, la solución práctica, está tan enraizada en la propia esencia y objeto de la ciencia, que viene a constituir su finalidad y su misma razón de ser. No se concibe en el campo del Derecho un estudio de un problema jurídico que no termine proponiendo una norma práctica de conducta, una solución adecuada a un problema planteado, o una interpretación racional a un precepto difícilmente aplicable a la vida. (...) El Derecho se nos muestra así, como una ciencia, como una unidad alcanzada mediante la

interpretaciones que se suministran a quien cursa para recibirse -y ejercer- de abogado (o de juez) en cualquiera de sus aspectos (...) deben contribuir a la realización del Derecho sustancial, a facilitar que la Jurisdicción a que lleve a buen fin su función, y que lo que importa es que el abogado en su amplísimo papel profesional -cuando aconseja, asiste, representa, orienta y gestiona-, sepa que está ayudando a alumbrar la solución y no a profundizar el problema." Cf. Morello (2005, p. 35-36)

36 Ramos (2004, p. 25): "La ciencia procesal (...) ha estado subiendo la montaña y retorna ahora al fondo de la ladera, como Sísifo. No es que nuestra misión sea una misión sin futuro, o una misión estéril, como es la condena de Sísifo. iNi mucho menos! Nuestra misión es operativa, nuestra misión se traduce luego en criterios prácticos porque, en definitiva, no olvidemos nunca que el elemento humano, sea abogado, sea parte, sea juez, es que el manipula el instrumento procesal. Nuestros trabajos son productivos". abstracción, pero también como un arte, como actividad de fines concretos. $^{37}$

\section{EL MÉTODO SOCRÁTICO Y EL USO DE NUEVOS MÉTODOS Y TECNOLOGÍAS DE ENSEÑANZA APRENDIZAJE}

Resulta manifiesto que la promoción del análisis socrático y el método del que hablamos no se opone a las modernas metodologías de aprendizaje, ${ }^{38}$ ni a los nuevos métodos ni modernas herramientas tecnológicas. Muy por el contrario: el permanente cuestionamiento de lo que viene dado, el debate en torno a las ideas, el estado permanente de alerta contrario a la "pereza del pensamiento" 39 es terreno fértil para la erradicación de lo que desde antiguo juristas y pedagogos repudian (pero algunos con muy poco entusiasmo): el viejo método catedrático. ${ }^{40}$

Superando ese escollo, pero sin soslayar que aún pervive en nuestras aulas universitarias, el método socrático permite el pleno desarrollo de las ejercitaciones

37 Cf. Gutiérrez (1974, p. 19-20).

38 Siguiendo los planteamientos de Carnelutti entendemos la metodología del Derecho como la ciencia de los métodos, tanto para su conocimiento y comprensión, cuanto para la enseñanza y aprendizaje del Derecho. Vide Carnelutti (2003, p. 13)

39 Nussbaum (2005, p. 43)

40 Reclamo que planteaban Pasquali y Calamandrei en L'Università di Domani. Véase Calamandrei (1961, p.29-30). El viejo y asentado método impide, además, el diálogo pedagógico: "El enseñante cree que debe y puede hablar, y cuanto más consistente y sólido sea su discurso, tanto mejor cree poder comunicar su doctrina; es el peligro de la cátedra, el profesor es incapaz de establecer el diálogo porque él es el auténtico transmisor de la ciencia." Cf. Aguilar (2003, p. 16). 
prácticas (vg. coloquios, búsqueda y análisis de jurisprudencia) destinadas a la comprensión de las instituciones jurídicas, no para reemplazar el estudio científico del Derecho, sino para "sustituir un método de enseñanza que condena a los alumnos a la inercia y a la parálisis mental, por un método que estimule sus iniciativas....". ${ }^{4}$ Somos de la idea que las ejercitaciones prácticas, realizadas por quienes van adquiriendo conocimientos sistemáticos sobre las instituciones jurídicas, son un método aptos no sólo para aplicarse en las facultades de Derecho de los países de la familia del Common Law, sino también para las nuestras herederas del sistema europeo continental. ${ }^{42}$ Baste para ello reparar que en el tradicional recurso de casación y en los más modernos medios de impugnación de efectos rescindentes, cuyo conocimiento corresponde a los más altos tribunales de nuestros países, las funciones nomofiláctica (en una versión remozada) y unificadora de la jurisprudencia, a pesar de las incompatibilidades sistémicas, están presentes en los modelos vigentes, fenómeno que exige de los abogados el permanente análisis crítico de las decisiones jurisdiccionales.

Existe hoy cierto consenso que el docente cumple antes una función de mediador entre el estudiante y el conocimiento que de mero depositario y trasmisor de éste. En este escenario, que supone un estudiante alerta, la irrupción de las tec-

41 Calamandrei, ibídem $36-37$.

42 Sobre el case system, véase Gutiérrez de Cabiedes (1974, p.22), y Martín Pastor, J.; Juan Sánchez, R. "La Docencia del Derecho Procesal en Europa". En PICÓ I JUNOY (Dir.) (2011, p.84). nologías de la información y de la comunicación (TIC's) es pertinente: el uso de las bibliotecas tecnológicas, las aulas de informática y los campus virtuales para el desarrollo de foros, la implementación de métodos de enseñanza aprendizaje para las modalidades e-learning, bi-learning, blended learning o para el uso de herramientas tan útiles como Moodle, Prezi o Adobe Presenter, es más eficiente en estudiantes activos y críticos que manifiestan sus opiniones, antes que con aquellos que pasivamente parecen escuchar del profesor todo lo que éste les dice.

Mas el llamado a pensar de un modo socrático auxiliados por el uso de las TIC's impone que el contenido nunca deba ser reemplazado por el medio; de lo contrario, en un contexto en que las ideas sean sustituidas por estímulos sensoriales, el pensamiento se empobrecería. ${ }^{43}$

\section{EL MÉTODO SOCRÁTICO Y EL DESARROLLO DE LAS COMPETENCIAS PROFESIONALES}

Avanzando sobre el curriculum basado en competencias, la Comisión Nacional de

43 Ello supone un uso adecuado de las TIC's. De acuerdo con un estudio, "la facilidad de acceso a Internet tiene el riesgo inevitable de empobrecer tanto la formación y el criterio del alumno, como disminuir su entrenamiento en el esfuerzo. En este sentido es interesante resaltar que el servicio público requiere ofrecer a la sociedad una formación cualificada, basada en una docencia-aprendizaje comprometida con la investigación, la razón y el espíritu crítico y obliga a tratar a los alumnos como titulares de un derecho público, nunca como meros clientes...". Cf. Chocrón Giráldez, A.; Tinoco Pastana, A. "La utilización racional de las nuevas tecnologías y la adaptación del método del caso en la enseñanza aprendizaje del Derecho Procesal". En PICÓ I JUNOY (Dir.) (2011) 374 (cursivas nuestras). 
Acreditación (CNA) de Chile ha declarado que el egresado de la carrera de derecho debe poseer, entre otras asociadas al conocimiento de las instituciones jurídicas, las siguientes cualidades:

- Posee habilidad para argumentar y razonar jurídicamente.

- Es capaz de analizar y resolver situaciones jurídicas, con un adecuado manejo de las fuentes, identificando los hechos relevantes, las normas y principios aplicables, y dando una solución al problema planteado.

- Es capaz de discernir y hacer valoraciones éticas con relación a normas o situaciones específicas y frente a posiciones o soluciones jurídicas. ${ }^{44}$

A todas luces la incorporación del método socrático en el curriculum moderno es necesario, puesto que razonar, argumentar, analizar, discernir y valorar, son todas acciones que desarrollan una o más competencias íntimamente vinculadas con el pensamiento crítico. Y esas acciones, que se encuentran en zonas medias de los dominios cognitivos ${ }^{45}$ pueden ser mejor desplegadas en un ambiente rico y estimulante, en que el profesor sea capaz de activar el pensamiento de sus estudiantes. ${ }^{46}$ El aula socrática parece ser el mejor ambiente para el desarrollo de esas competencias.

${ }^{44}$ CNA Chile.

45 Con referencia a la conocida Taxonomía de Bloom. Véase Kennedy (2007, p.24).

46 La figura del docente es irreemplazable en el aula socrática. Vide Nussbaum (2005, p.65).
Los abogados, profesionales que defendemos con eficacia y empeño los intereses o derechos de nuestros asistidos ${ }^{47}$ o que desde un estrado actuamos la función jurisdiccional, requerimos constantemente de un tábano cuyo aguijoneo permanente nos aleje del letargo confortable de la pereza mental de aceptar sin más las tradiciones y lo que siempre se ha hecho. ${ }^{48}$ Y siguiendo el ejemplo de Sócrates, maestro de tantos, una vida sin examen interior no vale la pena:

Quizá diga alguien: «-Pero, Sócrates, ¿no puedes desterrarte y llevar una vida tranquila y silenciosa?»

Esto es lo más difícil de haceros entender. Porque si os digo que eso sería desobedecer al dios y que, por ello, es imposible que lleve una vida tranquila, no me creeríais y pensaríais que hablo con ironía. Y menos me creeríais

47 Ideas que inspiran varias normas del Código de Ética Profesional de Chile:

«Artículo 25. Deber de correcto servicio profesional. Es deber del abogado servir a su cliente con eficacia y empeño para hacer valer sus intereses o derechos. Por eso, el abogado no debe asumir encargos que exceden sus conocimientos y capacidades profesionales.

El deber del abogado de servir al cliente no afectará su independencia ni comprometerá su conciencia. El abogado no puede exculparse de un acto ilícito atribuyéndolo a instrucciones de su cliente.»

«Artículo 26. Compromiso con la defensa de derechos del cliente. El abogado debe realizar las actuaciones y formular los argumentos dirigidos a tutelar los derechos de su cliente sin consideración a la antipatía o impopularidad que pudieren provocar en el tribunal, la contraparte o la opinión pública.»

48 Plat., Apol., I, XVIII. 
aún si digo que el mayor bien del hombre es conversar acerca de la virtud y de los otros temas que me habéis oído tratar cuando me examinaba a mí mismo y a los demás, y que una vida sin examen no vale la pena ser vivida. ${ }^{49}$

\section{HACIA UN AULA QUE PREGUNTE, DIALOGUE $Y$ PIENSE}

Pensar y dialogar, son dos actividades humanas y complementarias, a la vez que preguntar(se) y dialogar parecen inescindiblemente vinculadas; ellas suponen el reconocimiento del otro como representación de nuestra propia existencia en el mundo. ${ }^{50}$

La llamada pedagogía de la pregunta es una herramienta útil e idónea para provocar el pensamiento crítico en los aprendices, puesto que, reconociendo la alteridad, el arte de preguntar lleva hacia el conocimiento en un ambiente dialógico. Puestos en posición de enseñar, nos toca inducir a los aprendices en el arte de preguntar, rompiendo el esquema de la clase silenciosa en que sólo resuena la voz del enseñante. Para ello es necesario promover un ambiente colaborativo que rescate "el papel crítico-constructivo de

49 Plat., Apol., II, XVIII.

50 Gadamer (2001) 534

Interpretando las ideas del filósofo alemán, Zuleta (2005) escribe: "... preguntar y pensar son dos procesos intelectuales inseparables; primero, porque quien pregunta formaliza la búsqueda reflexiva del conocimiento; y segundo, porque si el hombre piensa y tiene conciencia de ello, puede así mismo plantearse preguntas y posibles respuestas; a partir de este necesario enlace se producen nuevos conocimientos." los educadores y de los alumnos"51, reconociendo en el lenguaje, en el habla, la herramienta adecuada para este complejo ejercicio dialéctico.

El pensamiento construye conocimiento cuando se comunica, en tanto que la comunicación facilita el aprendizaje. La lengua y el lenguaje, reconociendo la alteridad, permiten el aprendizaje, con el concurso de esos elementos que hemos destacado en el párrafo precedente. ${ }^{52} \mathrm{La}$ pregunta y la afirmación sólo tienen significado cuando vinculan a otros:

La palabra aislada es evidentemente un mero vocablo, es decir, sólo es el portador posible de un enunciado y no el mismo enunciado. Es cierto que hay que conocer las palabras aisladas y sus significados. De eso depende cualquier entendimiento mutuo en la vida con otros. En un intercambio lingüístico de esa naturaleza crece el mundo para nosotros y el nombrar consigue que se enriquezca en el uso lingüístico la fuerza nominadora de la palabra y en el uso de la misma lengua se forma la comunidad del mundo. ${ }^{53}$

51 Zuleta Araújo, ibídem.

52 "Creo que uno sólo puede aprender a través de la conversación" (traducción mía), declaraba HansGeorg Gadamer ante el Dietrich Bonhoeffer Gymnasium (Eppelheim, 19 de mayo de 1999), en el discurso a sus casi cien años de vida, explicando que sólo en la conversación el lenguaje tiene sentido (fulfil itself).

53 Gadamer (1997, p.88).

Interpretando el pensamiento del filósofo de Marburgo se ha escrito: "Cuando hablamos buscamos volvernos comprensibles al otro de modo que pueda respondernos, convalidarnos o rectificarnos. Todo esto forma parte de un auténtico diálogo. La 
A su vez la alteridad presupone el reconocimiento de la identidad cultural de quienes participan en un contexto dialógico, no como seres determinados por una herencia cultural, afirma Paulo Freire, sino capaces de superarse mediante un esfuerzo crítico educativo:

\section{(...) con la invención social del lenguaje, lado a lado con la op- eración sobre el mundo, pro- longamos el mundo natural, que no hicimos, que nos volvimos animales permanentemente in- scritos en un proceso de aprender y de buscar. (...). Queda clara la identidad de cada uno de no- sotros como sujeto, ya sea como educador o educando, en la prác- tica educativa. Y de la identidad entendida en esta relación con- tradictoria que somos nosotros mismos entre lo que heredamos y lo que adquirimos. ${ }^{54}$}

\section{CONCLUSIONES}

Hemos querido destacar la utilización del método socrático como una herramienta idónea a la enseñanza - aprendizaje del Derecho procesal, reconociendo que el fenómeno normativo se transforma y muta por el influjo de fuerzas modeladoras de naturaleza esencialmente evolutiva. Enfrentado el aprendiz ante el Derecho, ha de desarrollar determinadas competencias que le permitan identificar, com-

palabra empieza a ser palabra viva cuando es respuesta concreta a alguien concreto. (...) El fin de la educación es ser con los otros a través del diálogo y la comprensión, habitando la misma morada, que es el lenguaje." Cf. Aguilar (2003, p. 15).

54 Freire (2002, p. 104). prender, clasificar, sintetizar, comparar, aplicar y evaluar reglas y principios jurídicos, con la finalidad de desempeñarse en algunas de las actividades que ofrece el cada vez más vasto y variado campo profesional.

Las conductas arriba descritas, que no son sino manifestaciones concretas de estadios evolutivos del pensamiento -en la tradicional taxonomía del Bloom se desarrollan desde la fase del conocimiento hasta la de evaluación-, requieren, precisamente, activar el pensamiento crítico no sólo en quienes enseñan y aprenden derecho, sino también en quienes lo ejercitan en el foro de abogados y jueces, siendo el pensamiento crítico una conducta que distingue a los seres humanos y que se aprende y ejercita a diario.

Vemos en el llamado método socrático la sistematización de la práctica de generar conocimiento en comunidad por medio de la formulación de preguntas dirigidas, según el modo que el filósofo ateniense ejercitaba con sus discípulos y con todo aquél que fuese emplazado a pensar. Vemos en el pensamiento un arte, según guía los pasos que van desde la distinción de los elementos que constituyen las ideas hasta la contradicción (pensamiento como reflexión de sí mismo), a la vez que una actividad, pues su ejercitación se traduce en el discurso, el diálogo y la comunicación.

Para que el aprendizaje sea significativo requiere de la aplicación de métodos de enseñanza - aprendizaje dialógicos, que vinculen al aprendiz con su propio 
proceso de aprendizaje, con sus experiencias de vida, con su entorno social y con los otros aprendices en un proceso permanente de creación colectiva del conocimiento, guiado y garantizado por el enseñante. La sana práctica de formular preguntas a los aprendices, de motivarlos a preguntar y construir el conocimiento desde la conversación, activando el pensamiento crítico, parece ser una de las más idóneas y bellas metodologías para logar ese resultado.

El pensamiento crítico, activado por la práctica de formular preguntas dirigidas a la construcción dialógica del conocimiento, es un presupuesto necesario para el desarrollo de algunas de las más paradigmáticas competencias profesionales de los abogados: la habilidad de razonar y argumentar jurídicamente en contextos forenses y la de analizar y resolver situaciones jurídicas, proponiendo y evaluando soluciones idóneas a los intereses de los justiciables, requieren del pensamiento experimentado, cuando no del pensamiento probado, pues el pensamiento del abogado, por la enorme vocación práctica del Derecho, cualidad innegable en el derecho del proceso, no es un pensamiento que haya de quedarse habitualmente sólo en la esfera de las abstracciones sino que se dirige, como un estratega, a exhibir y demostrar la concreta utilidad del derecho en interés de las personas.

\section{REFERENCIAS BIBLIOGRÁFICAS}

Aguilar, L. A. (2003). Conversar para aprender. Gadamer y la educación. Sinéctica Revista Electrónica de Educación, (23): 11-18.

Bodenheimer, E. (1946). Teoría del Derecho (Traducido por Vicente Herrero) (2a). México: Fondo de Cultura Económica.

Calamandrei, P. (1961). La Universidad de Mañana (Traducción de Alberto Bianchi). Buenos Aires: EJEA.

Carnelutti, F. (2003). Metodología del Derecho. Buenos Aires: Valleta.

Couture, E. (1953). Los mandamientos del abogado $\left(3^{\mathrm{a}}\right)$. Buenos Aires: Depalma.

De Rivacoba y Rivacoba, M. (1981). Nueva crónica del crimen. Valparaíso: Edeval.

Devis Echandía, H. (2002). Teoría general del proceso. Buenos Aires: Editorial Universidad.

Ferrajoli, L. (1999). Derechos y garantías. La ley del más débil. Madrid: Trotta.

Freire, P. (2002). Cartas a quien pretende enseñar (8). México: Siglo Veintinuno.

Gimeno Sendra, V. (1981). Fundamentos del Derecho procesal. Madrid: Civitas.

Gadamer, H-G. (1997). Mito y razón (Trad. J. Francisco Zúñiga García). Barcelona: Paidós.

(2001). Education is Self-Education. Journal of Philosophy of Education, 35 (4): 529-538.

González Maura, V. y González Tirados, R. (2008). Competencias genéricas y formación profesional: un análisis desde la docencia universitaria. Revista Iberoamericana de Educación, 47 (2008): 185-209.

Gozaíni, O. (2005). Los protagonistas del Derecho procesal. Desde Chiovenda a nuestros días. Buenos Aires: Rubinzal-Culzoni.

Guitton, J. (2000). Nuevo arte de pensar. Madrid: Encuentro. 
Gutiérrez de Cabiedes, E. (1974). Enseñanza práctica del Derecho. En: Estudios de Derecho procesal. Pamplona: Universidad de Navarra.

Kennedy, D. (2007). Redactar y utilizar resultados de aprendizaje (Traducción de Hans Grof). Irlanda: UCC.

Maldonado López, A. (Ed.). (2015). Aprendizaje humano y pensamiento. Granada: EUG.

Morello, A. M. (2005). Formación de los operadores jurídicos. La Plata: Editora Platense.

Nussbaum, M. (2005). El cultivo de la humanidad. Barcelona: Paidós.

Ortega y Gasset, J. (1965). Misión de la Universidad (4ª). Madrid: Revista de Occidente.
Picó I Junoy, J. (Dir.). (2011). El aprendizaje del Derecho procesal. Barcelona: Bosch.

Ramos Méndez, F. (2004). El mito de Sísifo y la ciencia procesal. Barcelona: Atelier.

Tavolari Oliveros, R. (2000). El proceso en acción. Valparaíso: Libromar.

Unesco. Institute for Longlife Learning. (2010). Marco de acción de Belém. Disponible en: http://unesdoc.unesco.org/ images/0018/001877/187789m.pdf.

Zuleta Araújo, O. (2005). La pedagogía de la pregunta: una contribución para el aprendizaje. Educere, 9 (28): 115-119. 